\begin{tabular}{|l|l|l|l|l|l|l|}
\hline InterteXto & Uberaba & UFTM & $\begin{array}{c}\text { v. 4 } \\
\text { n. } 1\end{array}$ & p. 05-18 & 2011 - jan. / jul. & ISSN 1981-0601 \\
\hline
\end{tabular}

\title{
ESTUDO SOBRE ALGUNS CONCEITOS CONSIDERADOS FUNDAMENTAIS PARA A COMPREENSÃO DA TEORIA SÓCIO- HISTÓRICA DO FILÓSOFO RUSSO MIKHAIL BAKHTIN: UMA INVESTIGAÇÃO TEÓRICA
}

\author{
STUDY ABOUT SOME CONCEPTS CONSIDERED IMPORTANT TO THE \\ COMPREHENSION ABOUT THE SOCIAL-HISTORICAL THEORY OF THE \\ RUSSIAN PHILOSOPHER MIKHAIL BAKHTIN: A THEORETICAL \\ INVESTIGATION
}

Deize Fernandes Diniz ${ }^{1}$

\begin{abstract}
Resumo: Este artigo é resultado de um semestre de estudos voltados à obra de Mikhail Bakhtin, especialmente Marxismo e filosofia da linguagem (1981) e Estética da criação verbal (1997) e objetiva realizar uma revisão teórica sobre alguns conceitos que acreditamos serem fundamentais para uma melhor compreensão da teoria sóciohistórica bakhtiniana. Bakhtin, apesar de ter concepções bastante inovadoras na área da linguagem, era considerado uma figura marginal no cenário intelectual russo pósrevolucionário, por ser um estudioso multidisciplinar e por ser contrário a correntes acadêmicas específicas. Seu trabalho e suas ideias, mesmo tendo um reconhecimento tardio, são considerados, nos dias de hoje, de fundamental leitura e estudo a todos os profissionais que trabalham com o estudo da linguagem.
\end{abstract}

Palavras-chave: Mikhail Bakhtin; conceitos; teoria sócio-histórica; revisão teórica.

Abstract: This article is the result of some studies focused on the work of Mikhail Bakhtin, Marxism and the Philosophy of Language (1981) and Aesthetics of verbal creation (1997) and aims a theoretical review of some concepts that we believe are fundamental to a better understanding of his socio-historical theory. Bakhtin, despite having quite innovative concepts in the language section, was considered a marginal figure in the post-revolucionary Russian intellectual scene, because he was a multidisciplinary scholar and he was also against specific academic currents. His work and ideas, even taking a belated recognition, are considered, nowadays, the fundamental reading and study to all professionals which are involved in language's study.

Keywords: Michael Bakhtin; concepts; socio-cultural theory; theoretical review.

\section{Considerações iniciais}

O filósofo Mikhail Bakhtin foi uma figura marginal no cenário intelectual

\footnotetext{
${ }^{1}$ Aluna do Curso de Pós-Graduação em Letras da Universidade Federal de Santa Maria, na área de Estudos Linguísticos/bolsista CAPES e integrante do CEPESLI / UFSM (Centro de Ensino e Pesquisa em Línguas Instrumentais). ddinizz@yahoo.com.br
} 


\begin{tabular}{|l|l|l|l|l|l|l|}
\hline InterteXto & Uberaba & UFTM & $\begin{array}{l}\text { v. } 4 \\
\text { n. } 1\end{array}$ & p. 05-18 & 2011 - jan. / jul. & ISSN 1981-0601 \\
\hline
\end{tabular}

da Rússia pós-revolucionária por ser um estudioso multidisciplinar e por ser contrário a correntes acadêmicas específicas. Contemporâneo de Lev Vygotsky, Bakhtin também seguia uma orientação de cunho fortemente marxista.

Bakhtin reunia-se com profissionais das mais diferentes áreas tais como filósofos, literatos, músicos, etc., para discutir questões relacionadas à cultura. Esses grupos bastante heterogêneos tornaram-se conhecidos pelos chamados "Círculos de Bakhtin". Dentre os seus maiores colaboradores encontram-se Volochínov e Medviédiev que se tornaram amigos e grandes admiradores de Bakhtin.

As obras do autor russo só se tornaram conhecidas aqui no ocidente por volta da década de 1980, sendo que foi na década de 1990 que elas alcançaram maior prestígio e referencialidade. Dentre suas obras, damos especial destaque à obra Marxismo e Filosofia da Linguagem, que foi considerada inovadora, pois foi a primeira a abordar o estudo da linguagem, não mais de maneira isolada, mas sim associada a seu uso pela sociedade. Publicado pela primeira vez em Leningrado, em 1929, Marxismo e Filosofia da Linguagem saiu sob autoria de V. N. Volochínov.

Conforme esclarece Marina Yaguello na introdução do livro da edição do ano de 1981:

Segundo o professor $V$. V. Ivánov, amigo e aluno de Bakhtin,
haveria duas espécies de motivo: em primeiro lugar, Bakhtin
teria recusado as modificações impostas pelo editor (...). A
outra ordem de motivos seria mais pessoal e ligada ao caráter
de Bakhtin, ao seu gosto pela máscara e pelo desdobramento
e também, parece, à sua profunda modéstia científica (1981,
p.12).

Neste trabalho, optaremos por não entrar nesta questão de autoria por se tratar de um assunto que não cabe ao nosso propósito neste momento. Apenas queremos deixar claro que, por questões formais, faremos a citação da 


\begin{tabular}{|l|l|l|l|l|l|l|}
\hline InterteXto & Uberaba & UFTM & $\begin{array}{l}\text { v. } 4 \\
\text { n. } 1\end{array}$ & p. 05-18 & 2011 - jan. / jul. & ISSN 1981-0601 \\
\hline
\end{tabular}

obra com o nome de Bakhtin/Volochínov, 1981.

Essa obra, apesar de ter sido publicada há mais de oito décadas, mantém-se atual pela maneira pela qual aplica e explica a questão do materialismo dialético. Mesmo tendo sido escrita há bastante tempo ela continua sendo uma das obras mais estudadas em cursos universitários da área de letras, comunicação, etc., ou seja, em áreas que trabalham com o uso da linguagem.

Alguns autores afirmam que a linguística de Bakhtin pode ser considerada uma "trans-linguística" (Marques, 2004, Furlanetto, 1995), pois, para o autor, para que se possa compreender a língua, não se pode estudá-la isoladamente, mas sim dentro do contexto e do momento histórico no qual ocorreu determinada enunciação.

De acordo com Freitas:

A grande preocupação de Bakhtin ao criticar a linguística de seu tempo foi justamente mostrar a relação da linguagem com a realidade, enraizando-a na existência histórica dos homens. A comunicação verbal para ele não pode ser compreendida fora de sua ligação com a vida concreta. Assim, Bakhtin acrescenta ao aspecto meramente linguístico o contextual, necessário para a presença da dialogicidade. O enunciado produz-se num contexto que é social, portanto é sempre um diálogo, uma relação entre pessoas $(2005$, p. 312).

Assim sendo, Bakhtin procurou estudar a linguagem em situações de uso, ou seja, nos processos de interação social. Isto é, ele passou a considerar não só a presença física dos participantes de determinada enunciação, mas também o tempo histórico e o espaço social no qual ela ocorre.

Por entender que a Teoria Sócio histórica bakhtiniana é de fundamental importância a todo profissional que trabalha com estudos da linguagem, decidi realizar neste artigo um recorte teórico de alguns pontos que considero extremamente importantes para conhecimento e adequada compreensão de suas ideias. Sendo assim, primeiramente serão realizadas algumas 


\begin{tabular}{|l|l|l|l|l|l|l|}
\hline InterteXto & Uberaba & UFTM & $\begin{array}{l}\text { v. } 4 \\
\text { n. } 1\end{array}$ & p. 05-18 & 2011 - jan. / jul. & ISSN 1981-0601 \\
\hline
\end{tabular}

considerações sobre dialogismo, ideologia, signo e palavra. A seguir procuraremos trazer algumas noções sobre língua, interação verbal, enunciação e gêneros do discurso. Para finalizar, teceremos algumas considerações finais sobre o desenvolvimento do artigo.

\section{Dialogismo em Bakhtin}

Mikhail Bakhtin trazia o princípio dialógico como tema dominante em seus estudos. Para Gomes (2004, p. 144) o dialogismo em Bakhtin é entendido como sendo o "princípio ou teoria por meio da qual ele investiga as relações que o homem estabelece com o outro e com o mundo através da linguagem". Deste modo, para Bakhtin, o ser humano nunca é completo, pois sua existência depende do relacionamento estabelecido com os outros dialogicamente.

Conforme aponta Freitas ao escrever sobre Vygotsky e Bakhtin, o outro é imprescindível em suas teorias e acrescenta que sem o outro:

O homem não mergulha no mundo sígnico, não penetra na corrente da linguagem, não se desenvolve, não realiza aprendizagens, não ascende às funções psíquicas superiores, não forma a sua consciência, enfim, não se constitui como sujeito (2005, p. 305-306).

Isto significa dizer que, sem a presença do outro eu não me constituo enquanto sujeito. Daí entra o princípio da alteridade defendido por Bakhtin que esclarece que é no reconhecimento do outro que o indivíduo se constitui como tal e, ao mesmo tempo, ele também se altera constantemente. Além disso, é por meio do dialogismo que o homem vai deixar de ser explicado como fenômeno físico e passar a ser compreendido por suas ações.

Sobre este ponto Dahlet (apud Teixeira, 2006, p. 229) explica que "o dialogismo bakhtiniano se fundamenta na negação da possibilidade de conhecer o sujeito fora do discurso que ele produz".

A base do princípio dialógico para Bakhtin é a chamada "filosofia do 


\begin{tabular}{|l|l|l|l|l|l|l|}
\hline InterteXto & Uberaba & UFTM & $\begin{array}{l}\text { v. } 4 \\
\text { n. } 1\end{array}$ & p. 05-18 & 2011 - jan. / jul. & ISSN 1981-0601 \\
\hline
\end{tabular}

diálogo", que estabelece que o homem não é um ser individual, mas sim uma relação dialógica entre eu-tu, onde o "tu" é a condição de existência do "eu". Nesse caso, o "eu" não existe individualmente, senão como abertura para o outro.

Ao refletir sobre esta questão corroboramos com Flores e Teixeira quando elucidam que:

Nunca é demais salientar que a palavra "diálogo" em Bakhtin contraria entendimentos consagrados pelo senso comum. No sistema teórico do Círculo, diálogo não se reduz à interação face a face, isto é, "ao encontro fortuito de dois seres empíricos isolados e auto suficientes, soltos no espaço e no tempo, que trocam enunciados a esmo". Também não significa "entendimento", nem "geração de consenso". No conjunto da obra de Bakhtin, as relações dialógicas são entendidas como espaços de tensão entre vozes sociais (2005, p. 58).

Nesse sentido, podemos afirmar que o diálogo constitui uma das formas mais importantes de interação verbal, entendendo-se a palavra diálogo não somente como a comunicação em voz alta entre dois indivíduos, mas sim toda e qualquer comunicação verbal, seja ela oralizada ou não, independentemente do tipo ao qual pertence (Bakhtin/Volochínov, 1981).

\section{Ideologia, signo e palavra}

A ideologia, para Bakhtin/Volochínov (1981), é social e se constrói em todas as esferas das interações. Em Marxismo e Filosofia da Linguagem eles afirmam que:

Um produto ideológico faz parte de uma realidade (natural ou social) como todo corpo físico, instrumento de produção ou produto de consumo, mas ao contrário destes, ele também reflete e refrata uma realidade que lhe é exterior. Tudo que é ideológico possui um significado e remete a algo situado fora de si mesmo. Em outros termos, tudo que é ideológico é um signo. Sem signos não existe ideologia (1981, p. 31). 


\begin{tabular}{|l|l|l|l|l|l|l|}
\hline InterteXto & Uberaba & UFTM & $\begin{array}{l}\text { v. } 4 \\
\text { n. } 1\end{array}$ & p. 05-18 & 2011 - jan. / jul. & ISSN 1981-0601 \\
\hline
\end{tabular}

Em outras palavras, o signo para Bakhtin/Volochínov por ser de natureza social é concebido como um produto ideológico (ideológico no sentido de que integra alguma natureza material seja ela massa física, cor, som, etc.). Como parte de uma realidade, mas contrariamente a um corpo físico, ele reflete e refrata outra realidade que é exterior a ele, isto é, o signo possui um significado que the é inerente e, ao mesmo tempo, remete a algo que está fora de si mesmo.

$\mathrm{Na}$ introdução de Marxismo e Filosofia da Linguagem lê-se que "Todo signo é ideológico, a ideologia é um reflexo das estruturas sociais, assim, toda modificação da ideologia encadeia uma modificação da língua" (1981, p. 15). Portanto, pode-se dizer que o signo não se constitui fora de uma realidade concreta, pois ele somente emerge e pode existir dentro do processo de interação verbal. Sendo assim, Bakhtin/Volochínov reiteram essa ideia afirmando que o signo e a situação social no qual ele está inserido estão indissoluvelmente ligados e que o signo não pode ser separado da situação social sem ter alterada a sua natureza semiótica (1981).

Já, a palavra para Bakhtin/Volochínov (1981) é considerada o signo ideológico por excelência. Os autores defendem a posição de que ela serve como reflexo das condições do meio social, ou seja, que ela é o indicador das mudanças sociais. A seguir veremos como é que eles próprios elaboram essa ideia:

A palavra constitui o meio na qual se produzem lentas acumulações quantitativas de mudanças que ainda não tiveram tempo de adquirir uma nova qualidade ideológica, que ainda não tiveram tempo de engendrar uma forma ideológica nova e acabada. A palavra é capaz de registrar as fases transitórias mais íntimas, mais efêmeras das mudanças sociais (1981, p. 41)

E, mais adiante, reforçam essa tese expondo que "a palavra... reflete sutilmente as mais imperceptíveis alterações da existência social” (p. 46). 


\begin{tabular}{|l|l|l|l|l|l|l|}
\hline InterteXto & Uberaba & UFTM & $\begin{array}{l}\text { v. } 4 \\
\text { n. } 1\end{array}$ & p. 05-18 & 2011 - jan. / jul. & ISSN 1981-0601 \\
\hline
\end{tabular}

De acordo com suas concepções, a palavra não pertence a ninguém e está sempre à disposição de qualquer ser humano e sujeita a qualquer juízo de valor. Sobre este assunto os autores argumentam que:

$\mathrm{Na}$ realidade, não são palavras que pronunciamos ou escutamos, mas verdades ou mentiras, coisas boas ou más, importantes ou triviais, agradáveis ou desagradáveis, etc. A palavra está sempre carregada de um conteúdo ou de um sentido ideológico ou vivencial. É assim que compreendemos as palavras e somente reagimos àquelas que despertam em nós ressonâncias ideológicas ou concernentes à vida (1981, p. 95).

Nesse sentido, é ela, a palavra, o material privilegiado da comunicação na vida cotidiana, sendo que o seu sentido é totalmente determinado pelo contexto no qual ela foi proferida. É a palavra, também, o material semiótico da vida interior, ou seja, a responsável pela formação daquilo que Bakhtin/Volochínov (1981) denominaram de consciência, que nesse âmbito só se torna consciência quando está impregnada de conteúdo ideológico, isto é, somente por meio do processo de interação social.

Conforme elucidam Bakhtin/Volochínov:

$\mathrm{Na}$ realidade, toda palavra comporta duas faces. Ela é determinada tanto pelo fato de que procede de alguém, como pelo fato de que se dirige para alguém. Ela constitui justamente o produto da interação do locutor e do ouvinte. Toda palavra serve de expressão a um em relação ao outro. Através da palavra, defino-me em relação ao outro, isto é, em última análise, em relação à coletividade. A palavra é uma espécie de ponte lançada entre mim e os outros. Se ela se apóia sobre mim em uma extremidade, na outra apóia-se sobre o meu interlocutor (1981, p. 113).

Ou seja, nesta passagem os autores buscaram dar destaque a questão de que a palavra se posiciona sempre no espaço entre eu - outro. Deste modo, pensamos ser relevante expressar aqui que a palavra para Bakhtin/Volochínov 


\begin{tabular}{|l|l|l|l|l|l|l|}
\hline InterteXto & Uberaba & UFTM & $\begin{array}{l}\text { v. } 4 \\
\text { n. } 1\end{array}$ & p. 05-18 & 2011 - jan. / jul. & ISSN 1981-0601 \\
\hline
\end{tabular}

é interior quando está relacionada diretamente ao psiquismo e, no momento em que ela é inserida no meio social, ela passa a ser exterior.

\title{
Língua e interação verbal
}

Para Bakhtin/Volochínov (1981) a língua é a expressão das relações e das lutas sociais. Eles defendem que o seu lugar é o lugar das relações sociais, definido como o espaço de confronto e de conflitos ideológicos. Para os autores:

\begin{abstract}
A verdadeira substancia da língua não é constituída por um sistema abstrato de formas linguísticas, nem pela enunciação monológica isolada, nem pelo ato psicofisiológico de sua produção, mas pelo fenômeno social da interação verbal, realizada através da enunciação ou das enunciações. A interação verbal constitui assim a realidade fundamental da língua (1981, p. 123).
\end{abstract}

Nessa citação Bakhtin/Volochínov criticam as concepções de língua defendidas pelo objetivismo abstrato e pelo subjetivismo individualista. Para eles, a fala, a enunciação é que deve ser valorizada. Nesse sentido, afirmam a natureza social da fala, pois acreditam que ela está "indissoluvelmente ligada às condições da comunicação, que, por sua vez, estão sempre ligadas às estruturas sociais" (1981, p. 14).

Para eles, a língua é a materialização da linguagem humana verbalizada. Sendo resultado do trabalho humano, implica, ainda, dizer que ela é ideológica, isto é, é mais do que um sistema unirreferencial, pois assim como ela referencia o mundo imediato, ela também representa outro mundo que está além da imediatez interacional, ou seja, o contexto social mais amplo. Ainda, segundo os autores citados, a língua é vista como um "conjunto infinito de vozes sociais", isto é, vista a partir de seu uso real, ela possui a característica de ser dialógica.

Ao afirmar que "A língua vive e evolui historicamente na comunicação 


\begin{tabular}{|l|l|l|l|l|l|l|}
\hline InterteXto & Uberaba & UFTM & $\begin{array}{l}\text { v. } 4 \\
\text { n. } 1\end{array}$ & p. 05-18 & 2011 - jan. / jul. & ISSN 1981-0601 \\
\hline
\end{tabular}

verbal concreta, não no sistema linguístico abstrato das formas da língua nem no psiquismo individual dos falantes" (1981, p. 124) Bakhtin/Volochínov propõem uma nova ordem metodológica para o estudo da língua. Para eles, primeiramente são as relações sociais que evoluem, depois se segue que a comunicação e as interações verbais evoluem no conjunto das relações sociais. A seguir, ocorre que as formas dos atos de fala evoluem em consequência da evolução da interação verbal e, em seguida, esse processo evolutivo vai refletir, finalmente, nas mudanças das formas da língua.

Com relação a esta proposta de análise da língua, Geraldi caracteriza de forma excepcional o espaço onde se dão as interações entre os sujeitos:

Os sujeitos se constituem como tais à medida que interagem com os outros, sua consciência e seu conhecimento de mundo resultam como "produto" deste mesmo processo. Neste sentido, o sujeito é social já que a linguagem não é o trabalho de um artesão, mas trabalho social e histórico seu e dos outros e é para os outros e com os outros que ela se constitui (...). As interações não se dão fora de um contexto social e histórico mais amplo; na verdade, elas se tornam possíveis enquanto acontecimentos singulares, no interior e nos limites de uma determinada formação social, sofrendo as interferências, os controles e as seleções impostas por esta. Também não são, em relação a estas condições, inocentes. São produtivas e históricas, e como tais, acontecendo no interior e nos limites do social, constroem por sua vez limites novos (1991, p. 6).

A interação, para Bakhtin/Volochínov (1981), é um evento dinâmico no qual se colocam em jogo posições axiológicas, ou seja, é o instante em que entram em confronto os valores sociais dos indivíduos, além disso, eles consideram a interação verbal a realidade fundamental da língua. Os dois autores vinculam as interações verbais às interações sociais mais amplas, relacionando a noção não apenas a situações face a face, ou seja, os diálogos, mas também a outras situações enunciativas, aos gêneros discursivos, aos processos dialógicos, etc. 


\begin{tabular}{|l|l|l|l|l|l|l|}
\hline InterteXto & Uberaba & UFTM & $\begin{array}{l}\text { v. } 4 \\
\text { n. } 1\end{array}$ & p. 05-18 & 2011 - jan. / jul. & ISSN 1981-0601 \\
\hline
\end{tabular}

\section{Enunciação e gêneros do discurso}

A enunciação em Marxismo e Filosofia da Linguagem nada mais é do que a objetivação externa da atividade mental do indivíduo (1981, p. 117). Para Bakhtin/Volochínov a enunciação é:

Compreendida como uma réplica do diálogo social, é a unidade de base da língua, trata-se do discurso interior (diálogo consigo mesmo) ou exterior. Ela é de natureza social, portanto ideológica. Ela não existe fora de um contato social, já que cada locutor tem um "horizonte social" (1981, p. 16).

Por "horizonte social" entende-se o espaço-tempo compreendido em uma comunicação verbal, ou seja, o espaço-tempo do enunciado. Deste modo, a enunciação não parte de um sujeito individual isolado, mas sim é produto da interação entre indivíduos socialmente organizados e do contexto da situação social na qual ocorrem.

Para os referidos autores, toda enunciação possui dois níveis de significação, o tema e a significação. Por tema entende-se o sentido completo de uma enunciação que é dado não só pelos elementos verbais, como também pelos elementos extraverbais e pelo momento histórico em que ela é pronunciada. Já, a significação refere-se aos elementos que são reiteráveis e idênticos cada vez que são repetidos em uma enunciação, ou seja, ela pode ser considerada o estágio inferior da capacidade de significar, isto é, a significação da palavra no sistema da língua ou ainda da palavra dicionarizada. O tema seria, então, o estágio superior da capacidade de significar, a investigação da significação de uma palavra em uma enunciação concreta e contextualizada.

A enunciação sendo a objetivação externa da atividade mental (Bakhtin/Volochínov, 1981), o enunciado caracteriza-se como sendo a "unidade real da comunicação verbal" (Bakhtin, 1997, p. 294). Assim, como foi dito anteriormente, o sujeito só se constitui socialmente através de suas interações 


\begin{tabular}{|l|l|l|l|l|l|l|}
\hline InterteXto & Uberaba & UFTM & $\begin{array}{l}\text { v. } 4 \\
\text { n. } 1\end{array}$ & p. 05-18 & 2011 - jan. / jul. & ISSN 1981-0601 \\
\hline
\end{tabular}

com os outros indivíduos, sendo o diálogo face a face o principal tipo dessas interações.

Quando falamos produzimos enunciados que interpelam nosso interlocutor. O outro, no processo de compreensão e interpretação destes enunciados, vai nos oferecer a sua contrapalavra que é o que vai tornar, segundo Bakhtin/Volochínov, a relação falante-ouvinte dialógica, pois nas palavras dos autores "compreender é opor à palavra do locutor uma contrapalavra" (1981, p. 132). Nesses termos o sentido de toda e qualquer palavra dirigida a outrem só se completa na medida em que é compreendida pelo outro e dele recebe uma réplica de seu discurso.

Em Estética da Criação Verbal, Bakhtin complementando essa ideia afirma que:

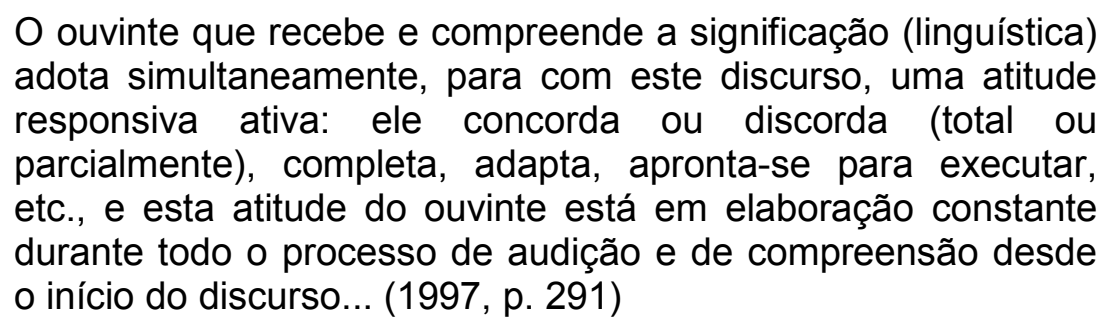

Com essa concepção de "atitude compreensiva ativa" Bakhtin reforça a tese de que cada sujeito é único e que ao ocupar um lugar único na existência, não pode escapar de sua responsabilidade existencial, ou seja, ele tem o dever social de responder ao seu interlocutor.

Com relação à utilização da língua, Bakhtin (1997) explica que ela se dá em todas as esferas da atividade humana e cada época e grupo social possui um repertório específico de formas de discurso, ou seja, cada época histórica tem sua linguagem particular, a linguagem de suas profissões, de seus grupos e instituições sociais, etc.. Assim sendo, pode-se dizer que a variedade dos gêneros de discurso é tão grande quanto a variedade das esferas da atividade humana. 


\begin{tabular}{|l|l|l|l|l|l|l|}
\hline InterteXto & Uberaba & UFTM & $\begin{array}{l}\text { v. } 4 \\
\text { n. } 1\end{array}$ & p. 05-18 & 2011 - jan. / jul. & ISSN 1981-0601 \\
\hline
\end{tabular}

Considerando as palavras do autor em discussão, ele explica que "qualquer enunciado considerado isoladamente é, claro, individual, mas cada esfera de utilização da língua elabora seus tipos relativamente estáveis de enunciados, sendo isso que denominamos de gêneros do discurso" (1997, p. 280). Isso implica dizer que, quando falamos, fizemos uso de diversos tipos de gêneros discursivos que possuem uma forma e estrutura consideradas padrão, porém isso se dá de forma inconsciente, pois no momento de uma enunciação não nos pusemos a pensar e a decidir qual gênero iremos utilizar, isso se dá de forma natural, quase que automática. Isso ocorre pelo fato de que utilizamos os mais variados gêneros na realização de nossa fala e, muitas vezes, desconhecemos que eles existem (Bakhtin, 1997).

Segundo o próprio Bakhtin:

Aprendemos a moldar nossa fala às formas do gênero e, ao ouvir a fala do outro, sabemos de imediato, bem nas primeiras palavras, pressentir-lhe o gênero, adivinhar-lhe o volume (a extensão aproximada do todo discursivo), a dada estrutura composicional, prever-lhe o fim (...). Se não existissem os gêneros do discurso e se não os dominássemos, se tivéssemos de criá-los pela primeira vez no processo da fala, se tivéssemos que construir cada um de nossos enunciados, a comunicação verbal seria quase impossível (1997, p. 303).

Ou seja, é a partir do domínio que temos sobre os mais variados gêneros do discurso que faz com que possamos usá-los de modo eficiente e de maneira adequada em cada situação de comunicação verbal. Bakhtin, afirma ainda que a maneira pela qual nos apropriamos dos diferentes tipos de gênero, é semelhante ao aprendizado da língua materna, pois aprendemos a falar ouvindo e reproduzindo enunciados concretos nas interações com os outros. Desta forma, aprendemos a língua em conjunto com as formas assumidas pelos enunciados. Por tal motivo é que Bakhtin veio a afirmar que "aprender a falar é aprender a estruturar enunciados" (1997, p. 303). Assim sendo, vale ressaltar que não somos nós que criamos os gêneros. Nós apenas os modificamos ou adaptamos às nossas necessidades à partir de um repertório 


\begin{tabular}{|l|l|l|l|l|l|l|}
\hline InterteXto & Uberaba & UFTM & $\begin{array}{l}\text { v. } 4 \\
\text { n. } 1\end{array}$ & p. 05-18 & 2011 - jan. / jul. & ISSN 1981-0601 \\
\hline
\end{tabular}

de gêneros do discurso que nos foi deixado de herança pelas gerações precedentes.

\section{Considerações finais}

Com a conclusão deste estudo teórico, no qual procuramos destacar alguns conceitos considerados, por nós, fundamentais para o entendimento adequado das obras e da teoria sócio histórica bakhtiniana tais como noções de interação verbal, dialogismo, ideologia, signo, enunciação, gêneros discursivos, etc., nos foi possível constatar que todos esses aspectos estudados estão fortemente integrados ao estudo da língua.

Além disso, este breve estudo serviu para nos mostrar, de forma bastante sucinta, a importância do legado deixado por Bakhtin às gerações posteriores a ele sobre os estudos da linguagem, pois, como sabemos, ele foi o pioneiro no estudo da língua em situações reais de uso, ou seja, foi ele o primeiro a levar em consideração, no processo enunciativo, a presença física dos interlocutores, o tempo histórico e o contexto de interação. A elaboração deste trabalho proporcionou, também, a oportunidade de melhor compreender as concepções de Bakhtin sobre os temas aqui abordados e realizar uma melhor sistematização de suas ideias.

Nesse sentido, estamos conscientes que apesar de Mikhail Bakhtin não ter sido um linguista, no sentido estrito do termo, suas contribuições aos estudos linguísticos foram e continuam sendo fundamentais, pois sua teoria, ainda hoje, segue servindo de base a muitos estudos relacionados ao uso da linguagem.

\section{Referências}

BAKHTIN, Mikhail. Estética da criação verbal. Tradução de Maria Ermantina Galvão G. Pereira. 2ªd. São Paulo, Martins Fontes, 1997. 


\begin{tabular}{|l|l|l|l|l|l|l|}
\hline InterteXto & Uberaba & UFTM & $\begin{array}{l}\text { v. } 4 \\
\text { n. } 1\end{array}$ & p. 05-18 & 2011 - jan. / jul. & ISSN 1981-0601 \\
\hline
\end{tabular}

; VOLOCHÍNOV, Valentin. Marxismo e Filosofia da Linguagem. Tradução de Michel Lahud e Yara Vieira. $2^{a}$ ed. São Paulo, Hucitec, 1981.

FLORES, Valdir do Nascimento; TEIXEIRA, Marlene. Introdução à linguística da enunciação. São Paulo: Contexto, 2005.

FREITAS, Maria Teresa de Assunção. Nos textos de Bakhtin e Vygotsky: um encontro possível. In: BRAIT, Beth (Org.). Bakhtin, dialogismo e construção do sentido. $2^{\mathrm{a}}$ ed. Campinas: Editora Unicamp, 2005. p. 295-314.

FURLANETTO, Maria Marta. Linguagem e Interação. Disponível em: http://ennan.multiservers.com/agatha 7031/inter.html, 1995.

GERALDI, João Wanderlei. Portos de Passagem. São Paulo: Martins Fontes, 1991.

GOMES, Neiva Maria Tebaldi. Em busca de um conceito de língua em Teorias da Enunciação. Letras de Hoje. Porto Alegre. v. 39, n 4, p. 137-150, dezembro, 2004.

MARQUES, Maria Celeste Said. Bakhtin: Apontamentos Temáticos. Primeira Versão. Porto Velho. v. XI, nº 161, p. 2-7, setembro, 2004.

TEIXEIRA, Marlene. O outro no um: reflexões em torno da concepção bakhtiniana de sujeito. In: FARACO, Carlos Alberto; TEZZA, Cristóvão; CASTRO, Gilberto de. Vinte ensaios sobre Mikhail Bakhtin. Petrópolis, RJ: Vozes, 2006. p. 227-234. 